\title{
LA NIEVE EN LOS PICOS DE EUROPA: IMPLICACIONES GEOMORFOLÓGICAS Y AMBIENTALES
}

\author{
J. J. GONZÁLEZ TRUEBA( ${ }^{(1)}$ y E. SERRANO CAÑADAS(2)
}

(1) Dpto. Geografía, Prehistoria y Arqueología. Universidad del País Vasco (UPV), C/ Tomás y Valiente, s/n, 01006, Vitoria-Gasteiz (Álava)

(2) Dpto. Geografía. Universidad de Valladolid (UVA)

Correo electrónico de contacto: juanjose.gonzalez@ehu.es

\begin{abstract}
RESUMEN. Los Picos de Europa son el máximo exponente de la alta montaña atlántica del SW de Europa. Su cercanía a la costa cantábrica, a tan sólo $20 \mathrm{~km}$, y altitud, por encima de los 2.600 m.s.n.m., hacen de los Picos de Europa una formidable barrera ante los frentes cargados de humedad procedentes del océano. Como resultado de estos particulares caracteres geográficos, en la alta montaña se generan frecuentes e intensas precipitaciones que pueden superar los 2.500 $3.000 \mathrm{~mm} / a \tilde{n} o$, buena parte en forma de nieve. Se analiza la distribución espaciotemporal de la cubierta nival entendida como un factor fundamental para explicar la morfodinámica actual de estas montañas, así como algunos de sus particulares condiciones geoecológicas. El proceso dominante en la alta montaña de los Picos de Europa es la nivación, en combinación con la karstificación, la solifluxión y la gelifracción, todos ellos íntimamente relacionados con la cubierta nival, su distribución, características y duración. La nieve controla el régimen térmico e hídrico del suelo, pero también es un eficaz agente de modelado.
\end{abstract}

ABSTRACT. The Picos de Europa massif is the maximun exponent of the Atlantic High Mountain of SW Europe. The present day climate derive initially from its volume and altitude, with peaks of around $2.700 \mathrm{~m}$, and from its geographical location. Its proximity to the Cantabrian Sea, only $20 \mathrm{~km}$ away, defines it as an oceanic high mountain massif with wet winters $(2.500-3.000 \mathrm{~mm} /$ year). Its climate is characterised by warmer temperatures than other Iberian high mountain areas (Pyrenees and Sierra Nevada), and the distribution of snow in time and space, highly abundant, but unstable (wet snow), is a fundamental geoecological factor in the massif. In this work we have analysed the distribution and dynamic of the snow covering depends on factors such as altitude, topography, orientation, exposure and wind redistribution processes. At $1500 \mathrm{~m}$ the duration of the snow cover is $6 / 7$ months, whereas at over $2000 \mathrm{~m}$, a duration of around 8 months is estimated, though this is highly variable depending on several factors. The dominant process on the high mountain of Picos de Europa is the nivation, related to karst, 
solifluction and gelifraction. The duration and distribution of the snow cover dictates the seasonal variations of the meteorization (thermal regulation of the freezelthaw cycles on the ground), the availability of water on the slopes and the sediment transport. The nivation also is an effective morphological agent.

Palabras clave: nieve, alta montaña atlántica, procesos nivales, Picos de Europa, Cordillera Cantábrica.

Key words: snow, atlantic high mountain environment, nival processes, Picos de Europa, Cordillera Cantábrica.

\section{Introducción}

Los Picos de Europa constituyen un macizo de alta montaña, individualizado y con entidad geográfica propia, situado al norte de la divisoria cantábrica, a tan sólo $20 \mathrm{~km}$ de la costa. Esta localización geográfica, junto con su altitud, cercana a los $2.700 \mathrm{~m}$ (Torre de Cerredo 2.648 m, Macizo Central), su volumen montañoso, el dominio calcáreo, así como una morfología agreste y vertical, con desniveles de más de $2.300 \mathrm{~m}$, hacen de él un medio de alta montaña oceánica. En los Picos de Europa, la alta montaña alcanza la máxima expresión de toda la cadena cantábrica, por su altitud, volumen, fisiografía, paisaje y variedad geográfica, constituyendo así, el máximo exponente de la alta montaña atlántica del suroeste de Europa.

El conjunto abarca aproximadamente unos $500 \mathrm{~km}^{2}$, con un desarrollo latitudinal de $15 \mathrm{~km}$, y longitudinal de $35 \mathrm{~km}$, dividido en tres macizos claramente diferenciados: el Macizo Occidental o del Cornión, el Macizo Central o Los Urrieles y el Macizo Oriental o de Andara. En conjunto forman un área de abrupta orografía, con un relieve compartimentado y de contrastes, donde vertiginosas crestas rocosas, culminadas por cumbres por encima de los $2.600 \mathrm{~m}$, contrastan con profundas depresiones, desfiladeros estrechos y encajados -como los esculpidos por los ríos Deva, Cares, Dobra y Sella-, y valles profundos y amplios, como los de Sajambre, Valdeón y Liébana, a escasos cientos de metros sobre el nivel del mar (Fig. 1). Predomina, de modo casi absoluto, la roca caliza del carbonífero superior, dispuesta en función de varias escamas cabalgantes alineadas de norte a sur, con rampas dorsales que siguen el buzamiento de los materiales tendidos hacia el norte y frentes de cabalgamiento que generan escarpes potentes y abruptos orientados al sur (Marquínez, 1988; Marquínez y Adrados, 2000). Sobre esto ha actuado, de forma variable en tiempo y espacio, una incesante erosión fluvial, la siempre presente karstificación -superficial y subterránea-, y especialmente, el labrado ejercido por los glaciares cuaternarios. A todo ello, hay que añadir una intensa dinámica de laderas, debido a las fuertes pendientes y desniveles existentes, y una dinámica geomorfológica asociada al frío y la nieve, especialmente activa en la parte superior de la montaña. De este modo, la alta montaña se caracteriza por el dominio de las grandes 


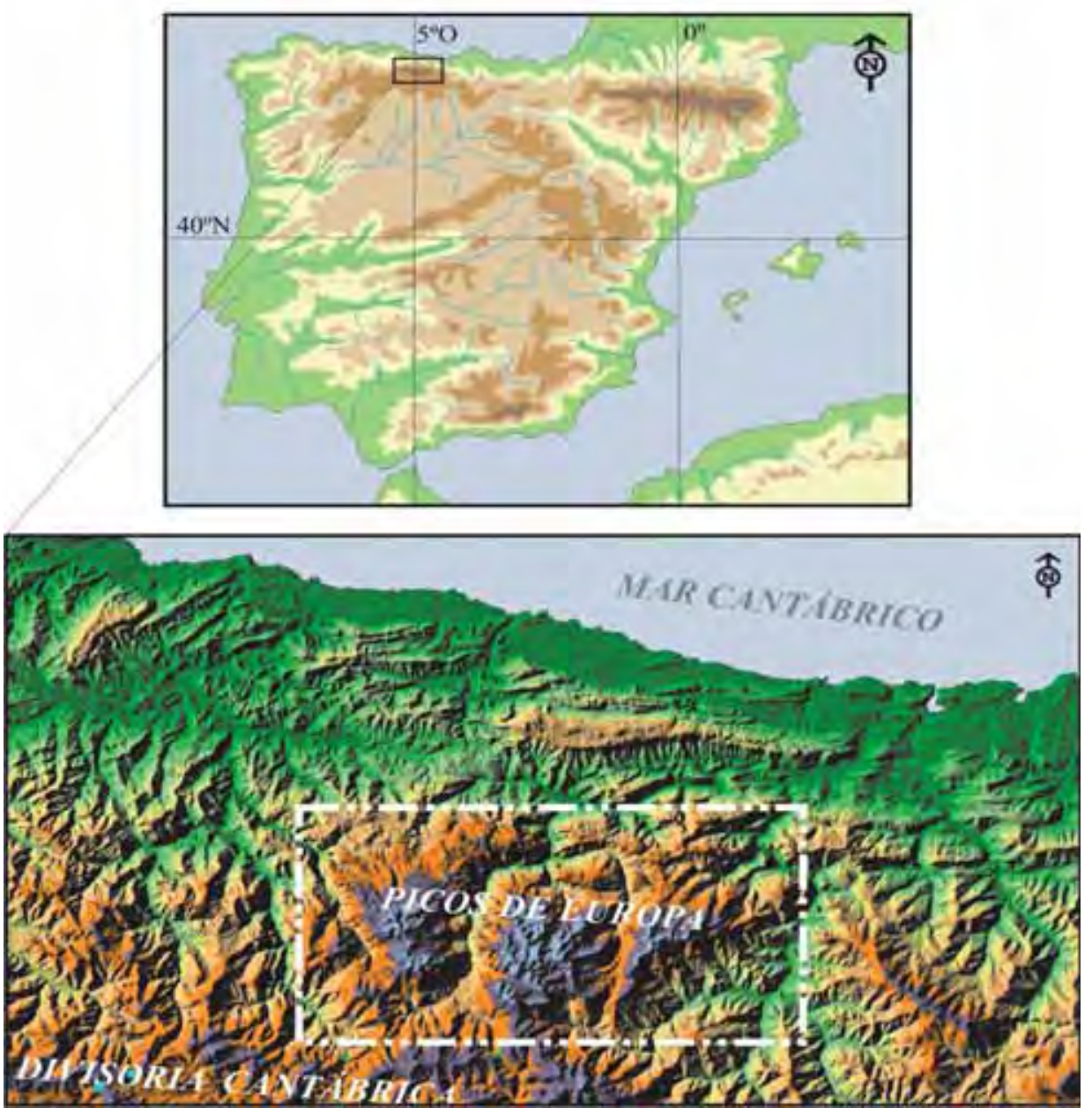

Figura 1. Localización geográfica del área de estudio.

formas de erosión glaciar o glaciokársticas. En la actualidad, por encima de los $1.800 \mathrm{~m}$, la alta montaña se caracteriza por un ambiente de tipo nivoperiglaciar (Serrano y González Trueba, 2004; González Trueba, 2007a, 2007b). De este modo, la nieve se presenta como un factor geoecológico clave en los Picos de Europa.

La importancia morfológica de la nieve en los Picos de Europa fue puesta de manifiesto por Miotke (1968), en su precursor estudio del Macizo Occidental, y posteriormente, apuntado en aportaciones sobre la morfodinámica actual (Castañón y Frochoso, 1998; Serrano y González Trueba, 2004), y en trabajos de síntesis que incluyen a los Picos de Europa (Brosche, 1978, 1994; Clark, 1981; González Martín, 1984, Castañón y Frochoso, 1994). Sin embargo, su estudio no ha sido abordado en detalle hasta trabajos recientes (González Trueba, 2007a, 2007b; González Trueba y Serrano, 2009). 


\section{Metodología}

La falta de registros térmicos y pluviométricos lo suficientemente representativos para la alta montaña de los Picos de Europa, no permite realizar por el momento una caracterización climática detallada de la alta montaña. En la actualidad, los únicos datos existentes en el cinturón de alta montaña, aunque muy puntuales y fragmentarios, son los recogidos en la estación superior del teleférico, a 1.834 m, y en la estación base, en Fuente Dé, a $1.068 \mathrm{~m}$. Esta carencia de datos base obliga a recurrir a la extrapolación de las observaciones y datos provenientes de estaciones situadas en la periferia del macizo y a muy baja cota. Para el estudio del manto nival se dispone de los datos del Programa EHRIN, las campañas de observación propias realizadas desde el año 2001, y la información indirecta aportada por técnicas de prospección auxiliares como la medición de la temperatura basal del manto nival (B.T.S.) y el control del régimen térmico del suelo mediante 12 termoregistradores (UTL-1) situados entre los 1.000 y 2.550 m.s.n.m. con registros de datos entre 2005 y 2007. El análisis de los datos obtenidos a través de los termoregistradores, atendiendo a distintas escalas temporales y espaciales, aporta una interesante información directa sobre el régimen térmico del suelo, e indirecta sobre la evolución temporal del manto nival, la presencia de agua o por contrario el congelamiento de la formación superficial, la existencia o no de permafrost, así como la dinámica geomorfológica inducida por todos estos factores (Haeberli, 1985; King, 1990).

El establecimiento de los procesos morfogenéticos básicos y las formas resultantes permite una mejor comprensión de la dinámica geomorfológica de alta montaña en los Picos de Europa. Para ello, la confección de la cartografía geomorfológica a escala 1:25.000 de los tres macizos (González Trueba, 2007b; González Trueba \& Serrano, 2009; González Trueba et al., 2009), ha permitido inventariar las formas y procesos implicados y establecer las relaciones espaciales y altitudinales con otras formas heredadas o activas. La descripción detallada de perfiles y la clasificación de las formas como activas e inactivas, así como su utilización como indicadores de procesos nivales y nivoperiglaciares o de las condiciones ambientales (Harris, 1988; Karte, 1983; Kotarba et al. 1987; Francou,1988), permite reconocer, describir y clasificar los procesos fundamentales involucrados en la morfogénesis actual, las asociaciones de procesos que definen los sistemas morfodinámicos y los límites morfológicos altitudinales (Chardón, 1984).

\section{La nieve en los Picos de Europa: distribución espacio-temporal, características e implicaciones en el régimen térmico/hídrico del suelo}

La localización geográfica en fachada oceánica, su emplazamiento paralelo a la costa y las características topográficas de los Picos de Europa condicionan en buena medida su régimen de precipitaciones, con diferencias importantes según la fachada y la altitud. Si en el fondo de los valles de la vertiente norte se estiman precipitaciones en torno a 1.000-1.200 mm/año, en el sur se reducen prácticamente a la mitad, como consecuencia del efecto de sombra pluviométrica que ejerce el propio macizo. Mientras 
tanto, en la zona de cumbres se estiman precipitaciones por encima de los 2.500-3.000 mm/año (Muñoz Jiménez, 1982).

Teniendo en cuenta el escalonamiento térmico altitudinal representado en la Figura 2, durante los meses de noviembre a abril, buena parte de las precipitaciones que se producen en la alta montaña son en forma de nieve. Por el contrario entre mayo y septiembre predominan los aportes en forma de lluvia.

La topografía compleja y las pendientes muy contrastadas de los Picos de Europa, favorecen la existencia de importantes diferencias en la distribución y profundidad del manto nival. La tasa de acumulación y permanencia de la nieve, en función de la pendiente del terreno, puede dar diferencias del orden de varios metros entre las laderas y umbrales más o menos pendientes y el fondo de las depresiones glaciokársticas, donde se acumulan espesores de más de 3-4 m.

En lo que respecta a la distribución temporal de la nieve, a parte de las nevadas ocasionales que se puedan dar durante los meses de verano, las primeras nevadas llegan a finales de septiembre o principios de octubre, aunque no perduran por debajo de los 1.700-1.900 m. Esta primera capa de nieve, si se conserva, sirve de base para las nevadas más intensas que comienzan en noviembre y las primeras semanas de diciembre, donde la nieve llega a alcanzar cotas en torno a los $1.000 \mathrm{~m}$. Los meses de enero y febrero registran las condiciones térmicas más rigurosas y también nevadas frecuentes e intensas. El manto nival puede descender por debajo incluso de los $750 \mathrm{~m}$, con una distribución, continuidad y profundidad variables, hasta el fondo de las gargantas fluviales a poco más de $300 \mathrm{~m}$ (Fig. 3), durante algunas semanas.

La sobreacumulación de nieve debido a la abundancia de las precipitaciones y las condiciones atmosféricas, no excesivamente frías, favorecen el desarrollo de aludes. La acu-

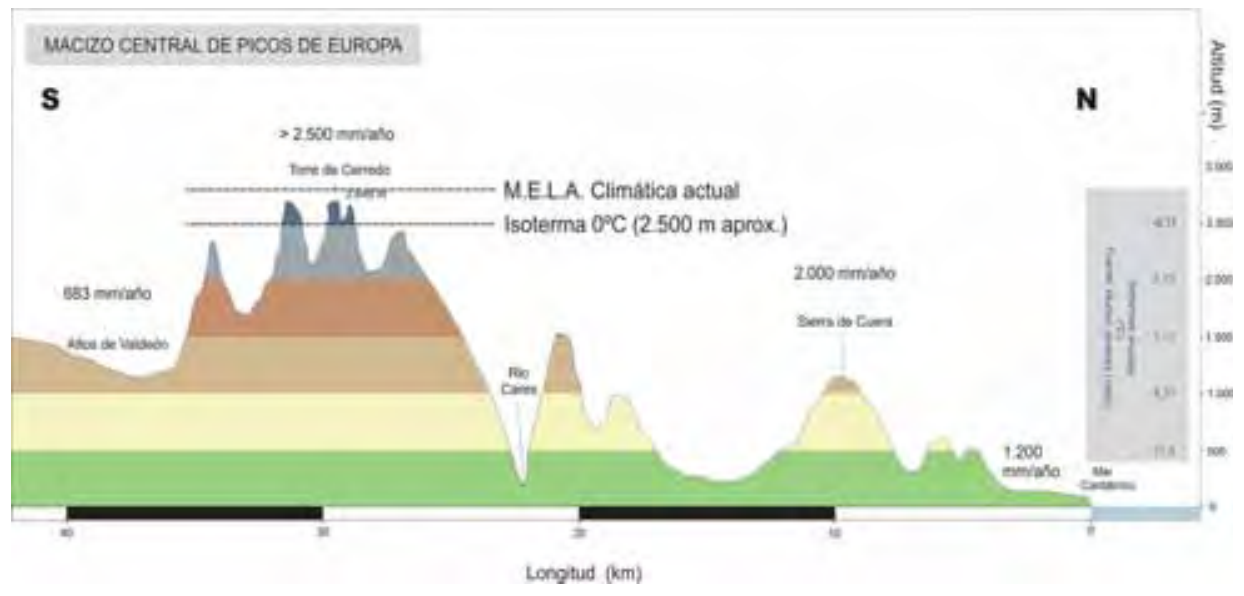

Figura 2. Condiciones climáticas generales de los Picos de Europa. 

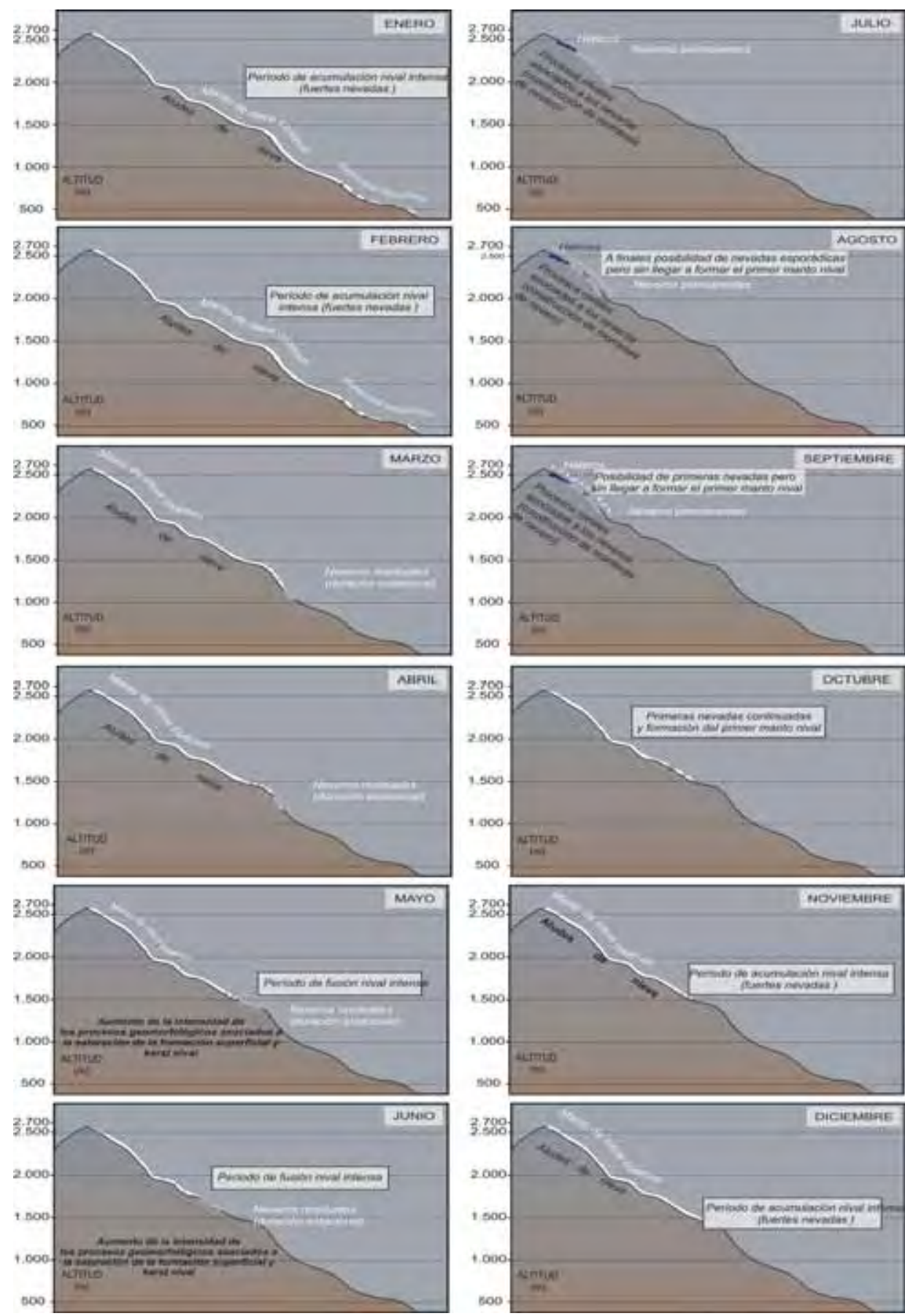

Figura 3. Evolución estacional del manto nival y sus implicaciones geomorfológicas en los Picos de Europa. 
mulación de nieve a los pies de algunas canales de aludes, favorece su consolidación y permanencia a cotas relativamente bajas, de forma que su fusión induce el desarrollo de procesos geomorfológicos indirectos, generalmente por saturación de la formación superficial.

A finales de marzo, la fusión es cada vez mayor en las partes bajas, de forma que el manto nival tiende a fragmentarse, a favor de la persistencia de nieve aprovechando los abrigos topográficos. A finales de mes sólo perdura por encima de los 1.100-1.250 m. Es durante los meses de abril, y sobretodo mayo y junio, cuando el ascenso de las temperaturas favorece un aumento de la fusión generalizada. En este sentido, la variabilidad interanual produce importantes diferencias motivadas por nevadas tardías que alargan la tendencia evolutiva típica, retrasando la fusión nival en cotas bajas con ritmos decenales, como ocurrió en 1996 y 2009. Por lo general entre finales de abril y a lo largo de todo el mes de mayo, la cubierta de nieve más o menos profunda $(30-125 \mathrm{~cm})$, se mantiene por encima de los 1.750-1.900 m.

A finales de junio, el manto de nieve se mantiene por encima de los $2.000 \mathrm{~m}$, mientras que por debajo tan sólo se conservan pequeñas acumulaciones de nieve en abrigos con topografía y exposición favorables (dolinas y circos de orientación norte) o puntos de acumulación de nieve por avalanchas (salidas de principales canales de aludes). La amplia variabilidad del manto nival hace que sea difícil establecer un período de fusión por encima de los 2.000 de altitud, pues hay años en los que se conserva hasta mediados de junio a 1.900-1.950 m (1996, 2009), mientras que otros años la cubierta de nieve es muy escasa y fragmentada desde finales de marzo (2001). Además, en los Picos de Europa los procesos de fusión no sólo están en relación con el ascenso progresivo de las temperaturas, también se asocian a fenómenos esporádicos como el viento sur y el efecto föehn en primavera, o con las precipitaciones de carácter tormentoso, frecuentes en el macizo durante esos meses, y que liberan grandes cantidades de agua en intervalos de tiempo muy cortos, lo cual tienen importantes implicaciones morfodinámicas.

Entre julio y agosto se funde progresivamente la mayor parte de la cubierta nival. Pero por encima de los 2.100-2.200 m, se pueden conservar pequeños neveros más o menos permanentes, a favor de localizaciones favorables, aprovechando las condiciones de abrigo que ofrece el terreno: umbrías, pies de pared, salidas de canales de aludes, fondos de jous y depresiones menores (dolinas, entradas de simas y cuevas). Como vemos la exposición y topografía de las crestas son los factores fundamentales que guían la distribución de dichas manchas de nieve residual. Por otro lado, en los años más secos, como los veranos de los años 2003 y 2008, las altas temperaturas registradas provocan la fusión de la mayor parte de los neveros permanentes, quedando al descubierto tan sólo los heleros, residuos heredados del avance glaciar histórico de la Pequeña Edad del Hielo (González Trueba, 2007a, 2007b, 2007c).

En la alta montaña, las fases generales diferenciadas dentro de la evolución anual de las temperaturas del suelo presentan unos límites espaciales y temporales variables, en función de la altitud, las condiciones topoclimáticas, y la variabilidad meteorológica interanual, considerando la variación del régimen de temperaturas y, especialmente, la mayor variación interanual de las precipitaciones en forma de nieve. Cuando el espesor del manto nival es suficiente $(>80 \mathrm{~cm})$, ejerce una labor de aislante térmico del suelo con 
respecto a las condiciones atmosféricas del exterior. De esta forma, durante el invierno, con un manto de nieve estable, se produce una situación de homotermia que mantiene la temperatura del suelo en torno a $0^{\circ} \mathrm{C}$, reduciendo considerablemente la penetración de la onda de frío, así como el desencadenamiento de ciclos de hielo/deshielo. A partir de los registros térmicos de suelos se pueden establecer para la alta montaña de los Picos de Europa unos regímenes básicos de comportamiento del manto nival.

- Condiciones otoñales y emplazamiento del manto nival: Señalado por las primeras nevedas y el establecimiento del manto nival, es posible distinguir dos fases, con ligeras variaciones interanuales. Desde finales de octubre a noviembre la temperatura del suelo desciende hasta situarse ligeramente por encima de los $0^{\circ} \mathrm{C}$. El aumento del espesor de la cubierta de nieve reduce la influencia térmica atmosférica sobre el suelo y las primeras nevadas de importancia se traducen en algunas semanas con estabilización del régimen térmico del suelo, con temperaturas que oscilan entre $-0,2$ y $1^{\circ} \mathrm{C}$ a lo largo de noviembre. Los ciclos de hielo/deshielo se reducen drásticamente, y llegan a ser inexistentes en algunos de los años estudiados. En estas condiciones, posiblemente hay fusión nival en la base del manto, y quizás rehielo, con importantes implicaciones morfodinámicas que incluyen procesos de saturación, flujo, lavados, canalillos, etc.

- Equilibrio térmico invernal y estabilidad del manto nival: Desde mediados de diciembre el manto nival equilibra el régimen térmico del suelo, con temperaturas del suelo en torno a $0^{\circ} \mathrm{C}$, si bien es posible diferenciar dentro de este período ligeras variaciones interanuales. En algunos emplazamientos, en enero-febrero se observan variaciones leves de las temperaturas asociadas a la inestabilidad del manto nival. La posible disminución de la cubierta nival por fusiones rápidas o movimientos en masa desprotege la formación superficial y favorece el desarrollo de ciclos de hielo/deshielo, siempre con amplitudes térmicas muy modestas (1- $\left.2^{\circ} \mathrm{C}\right)$. Por otra parte, en otros emplazamientos más favorables para la estabilidad del manto nival, desde febrero, y durante casi 6 meses, hasta finales de julio en las zonas altas de la alta montaña, las temperaturas del suelo permanecen cercanas a $\operatorname{los} 0^{\circ} \mathrm{C}$, con amplitudes muy moderadas. A pesar de que la temperatura del aire y la intensidad de la radiación solar aumentan a medida que avanza la primavera, la cubierta nival aísla el suelo de dicho ascenso térmico atmosférico.

- Fusión del manto nival: Se observa de nuevo una clara relación entre la evolución de las temperaturas del suelo y la dinámica de la cubierta nival. La fusión del manto nival se registra nítidamente a finales de julio por encima de los 2.300 m. En Peña Vieja, donde hasta ese momento las temperaturas se mantienen estables $\left(-0,08^{\circ} \mathrm{C}\right)$, la fusión de la nieve produce un aumento de la humedad y la temperatura en la formación superficial, de forma que la temperatura de la parte superior del suelo asciende hasta valores próximos a $0^{\circ} \mathrm{C}$. La temperatura del suelo se mantendrá estable en esos valores, mientras la nieve no haya desaparecido completamente. A partir de ese momento, las temperaturas ascienden progresivamente, día a día, desde valores cercanos a $0^{\circ} \mathrm{C}$ y con amplitudes muy modestas $\left(1-2^{\circ} \mathrm{C}\right)$ hasta registrar las variaciones térmicas atmosféricas cuando 
aún no ha desaparecido completamente la cobertura nival. Una vez desaparecida la cubierta de nieve, el suelo vuelve a estar controlado directamente por las condiciones atmosféricas con regímenes térmicos invertidos en algunos termoregistradores de la alta montaña (González Trueba, 2007a). La velocidad de fusión de la nieve en áreas de alta montaña marginales de latitudes medias ha sido estimada en $5 \mathrm{~cm} /$ día como promedio (Delaloye, 2004), de modo que en función del espesor de la capa de nieve a finales de la primavera, el proceso anteriormente mencionado de fusión y alteración del régimen térmico del suelo, puede durar desde unos pocos días, cuando el espesor es de tan sólo unos pocos centímetros, hasta 30 y 40 días, allí donde la profundidad de la nieve supere los $2 \mathrm{~m}$. Este es el caso de los fondos de las principales depresiones glaciokársticas, las dolinas de las zonas altas y los circos en orientaciones septentrionales.

Como se ha podido comprobar para el área de estudio, además de su relación con la dinámica atmosférica regional, la evolución de las temperaturas del suelo está en estrecha relación con los factores topoclimáticos, entre los cuales la altitud y las características topográficas de cada emplazamiento (pendientes, rugosidad, orientación, -exposición y su relación con la tasa de radiación solar), junto a factores dependientes directamente de los anteriores como la distribución, características y evolución del manto nival, condicionan la evolución anual del régimen térmico del suelo, y con ello, la dinámica geomorfológica de la más alta montaña (González Trueba, 2007a). Los datos analizados en todos los termoregistradores, situados entre los 1.000 y $2.550 \mathrm{~m}$ (años 2005-2007), muestran un régimen térmico muy dependiente de la constitución y evolución del manto nival, de forma que las distintas fases en la evolución anual de las temperaturas del suelo pueden variar considerablemente tanto temporal (de un año a otro, en función de la variable acumulación de nieve), como espacialmente (en función de las condiciones topoclimáticas, y su influencia en la distribución del manto nival). El viento y el ritmo e intensidad de movilización y desplazamiento de nieve por avalanchas son también importantes factores en la distribución del manto nival que implica comportamientos térmicos del suelo muy variables (Tabla 1 y Fig. 4).

Junto a las diferencias derivadas de la altitud, la topografía implica una gran variabilidad espacial en la distribución y evolución del manto nival en la horizontal. El espesor de nieve es máximo en los fondos de las depresiones glaciokársticas, que a modo de grandes fondos de saco, son objeto de una sobrealimentación de nieve procedente de las paredes que los rodean, pudiendo alcanzar varios metros durante un gran número de meses al año. Junto a estas grandes formas, otras como dolinas, pies de pared, y especialmente en la salida de canales de aludes de nieve, suelen presentar un mayor espesor y duración de la cubierta nival, lo que influye en el régimen térmico, y en la funcionalidad y eficacia de los procesos asociados al frío y la nieve. Por el contrario, en las topografías con condiciones menos propicias a la acumulación y permanencia de la nieve, como es el caso de los umbrales entre jous, crestas y superficies venteadas, la influencia de las condiciones atmosféricas es mayor y presentan una mayor variabilidad temporal de su régimen térmico. Todo ello, se traduce en un incremento de los ciclos de hielo/deshielo, de la penetración de la onda de frío, y en temperaturas absolutas más bajas. 
Tabla 1. Matriz de síntesis de las interrelaciones entre la distribución del manto nival, el comportamiento térmico del suelo y otros factores geoecológicos a lo largo del año, y para la parte superior de la alta montaña de los Picos de Europa.
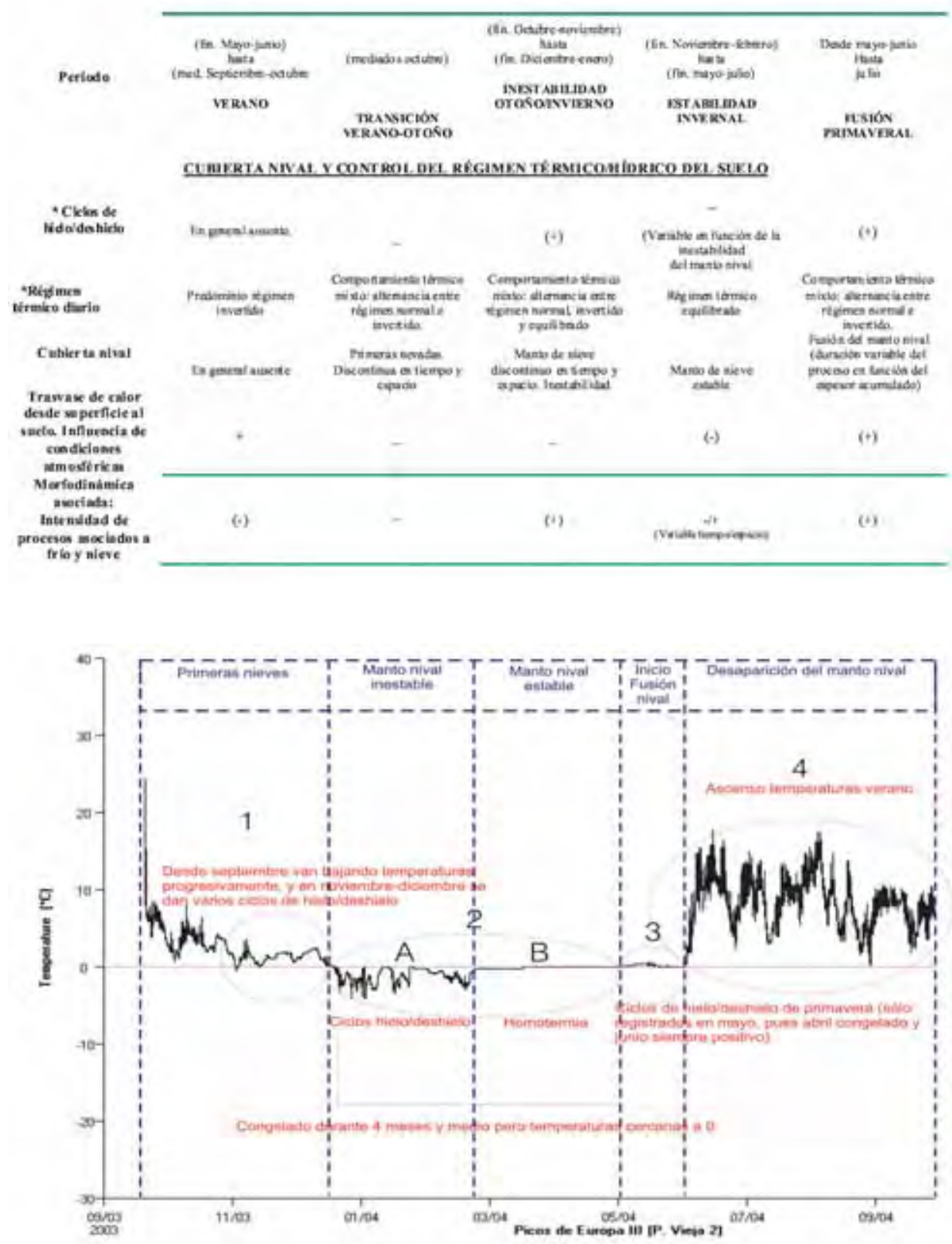

Figura 4. Gráfica con la evolución térmica del suelo y su relación con la distribución temporal del manto nival en la cara $O$ de Peña Vieja $(2.510$ m) (Macizo Central). Los números 1 al 4 señalan las fases evolutivas diferenciadas. 
De forma general, y considerando su variabilidad, los factores asociados a la nieve que condicionan el comportamiento térmico del suelo son la distribución y evolución del manto nival, incluyendo la variación anual (tiempo e intensidad) de las precipitaciones en forma de nieve, la redistribución de la nieve por la acción del viento y la redistribución de la nieve por acción de los aludes. En relación a la evolución anual, la fecha y ritmo de fusión y desaparición del manto nival (influencia de aludes, viento sur, etc.), la fecha de las primeras nevadas, la distribución (vertical/horizontal), espesor y características de la nieve (nieve seca o húmeda, manto estable o inestable, etc.) y la evolución del manto nival (González Trueba, 2007a).

\section{La nieve como agente de modelado: los procesos y formas nivales}

La mayor parte de los procesos geomorfológicos desencadenados en la montaña supraforestal están en relación tanto con la propia cubierta de nieve como agente de modelado, como por el aporte de agua derivado de su fusión. Como se ha visto, la altitud determina en buena medida la duración de la cubierta de nieve, que pasa a ser de 8/9 meses por encima de los $2.000 \mathrm{~m}, 6$ meses aproximadamente en torno a $1.500 \mathrm{~m}$ y ya de forma esporádica para el fondo de los valles, que en función de la variabilidad interanual pueden estar cubiertos de nieve desde días o semanas hasta 1 o 2 meses en los años de nevadas más intensas. La nieve es, de este modo, un elemento clave que condiciona el régimen térmico del suelo y los procesos morfodinámicos asociados al mismo. A su vez, la nieve es un elemento básico en el régimen hídrico de las laderas de montaña, representa un auténtico almacén de agua y su fusión suministra humedad al suelo durante gran parte del año. De este modo, el ritmo e intensidad de la fusión del manto nival condicionan, junto con los aportes de las lluvias, los procesos asociados a la saturación de la formación superficial, con un amplio cortejo de formas resultantes (Haeberli, 1985; Hoezle et al., 1999, Delaloye, 2004; Ishikawa, 2003).

Durante los períodos de fusión, y especialmente entre los meses de abril y mayo en la franja altitudinal entre 1.750-1.900 y 1.100-1.250 metros se incrementa la intensidad de los procesos geomorfológicos asociados a la fusión generalizada de la nieve y la saturación de la formación superficial, lo que puede desencadenar procesos de gran importancia en el sistema de transferencia de material. La morfodinámica asociada a la fusión nival genera tanto procesos de alta frecuencia y baja intensidad (solifluxión), como procesos de baja frecuencia pero de alta intensidad (flujos de derrubios). Los análisis realizados hasta el momento en Áliva denotan una actividad moderada que afecta sólo a las porciones superiores de las formaciones superficiales y cuya actividad se asocia al período de fusión primaveral. Como veremos más adelante, la cantidad de nieve y su duración tiene un significado fundamental en la formación de los procesos kársticos de detalle (karst nival).

\subsection{La nieve en movimiento: aludes de nieve y formas resultantes}

Los aludes implican movimientos en masa de la cubierta nival, que en función de las características, condiciones en las que se desarrollan y dinámica, pueden dar lugar a 
distintas tipologías y clasificaciones ya clásicas. Entre las morfologías asociadas de forma directa a los aludes de nieve podemos diferenciar dos: una forma asociada al proceso de erosión y transporte del material, constituida por el canal de evacuación; y otra asociada a la deposición de los materiales transportados por la nieve en su caída, y que provocan la construcción de conos de derrubios de tamaño variable. En la medida que ambos forman un sistema conjunto e indisociable de transferencia de materia y energía, la localización de los segundos va a estar controlada por los primeros, ya que la deposición del material se efectúa al pie de los canales de aludes, en la salida de evacuación de los mismos (Washburn, 1979; Ives, 1980, 1986).

Los aludes de nieve son un fenómeno muy frecuente en los Picos de Europa, y no sólo restringidos a la alta montaña, pues existen sectores como las Canales septentrionales de Ándara y El Cornión, las laderas septentrionales de Ándara (Jierru, Jidiellu, Brañiella) o Los Urrieles (Camburero y Balcosín), o en Fuente Dé, en los que llegan a conectar las zonas culminantes con los fondos de los valles a escasos $200 \mathrm{~m}$. La sobreacumulación de nieve derivada de las importantes precipitaciones favorece el desarrollo de aludes de magnitudes y frecuencias muy variables. En función de dicha magnitud y frecuencia (alta intensidad-baja frecuencia, baja intensidad-alta frecuencia) su efectividad geomorfológica también cambia, pues tan sólo los de mayores dimensiones y que afectan a las capas más profundas del manto nival realmente ejercen un arrastre de material importante. La efectividad de los aludes, pues, no se limita a la alta montaña, alcanzando las laderas bajas con fenómenos de alta intensidad capaces de remodelar la base de las canales, y en ocasiones pueden llegar a representar una elevada peligrosidad, con altos riesgo para vidas e infraestructuras humanas en la base de las canales. La vegetación, su distribución, recubrimiento, especies y fisonomía son un buen indicador del grado de frecuencia y peligrosidad de estos procesos geomorfológicos en Picos de Europa (González Trueba, 2007a; González Trueba y Serrano, 2009).

La nieve en los Picos de Europa es húmeda, como corresponde a un medio oceánico, de ahí que los aludes de nieve húmeda sean muy comunes, pero no son los únicos, pues también se registran aludes de placa de dimensiones notables. En la alta montaña los aludes son más frecuentes que en las partes bajas, debido a unas mayores tasas de acumulación y a la duración de la nieve durante más tiempo. Pero la intensidad del fenómeno es muy variable. Los frecuentes aludes de la alta montaña suelen ser más pequeños, de tipo superficial y de dimensiones medias, de forma que su capacidad morfológica suele ser nula o reducirse al arrastre del material previamente retrabajado y desgajado de las paredes, por lo que no son significativos como agentes morfológicos directos. Sin embargo, en años de nevadas intensas se generan aludes de fondo de mayores dimensiones capaces de movilizar grandes cantidades de material (suelo, derrubios, bloques, vegetación) y erosionar el sustrato por el que se desplazan, generando sus formas más representativas, los canales de aludes. La existencia de canales de gran desarrollo vertical que conectan sectores en torno a 1.800-2.000 con el fondo a 1.000-1.100 m, o incluso 200-300 m, pueden dar lugar a procesos de alta intensidad, con formas de mayores dimensiones, a pesar de sucederse con menor frecuencia. Por otro lado, los condicionantes topoclimáticos también tienen un papel destacado, de tal forma que la disposición de las crestas en relación a su 
orientación respecto a la llegada de los principales frentes y vientos dominantes (NO y ONO), la topografía de detalle, y la dinámica de la nieve en relación a su mayor o menor exposición ante la radiación solar directa, implican una efectividad y recurrencia de los aludes muy variable. A pesar de la alta heterogeneidad morfológica de los canales de aludes, dirigida por la complejidad morfotectónica y topográfica de las paredes rocosas, se ha establecido una tipología morfológica de canales de aludes válida para el conjunto de los Picos de Europa (González Trueba, 2007a, 2007b):

a) Canales de aludes de pequeño desarrollo: En los grupos altimontanos por encima de los 1.800-2.000 m, los canales de aludes son de menor desarrollo, pero muy numerosos y recurrentes, asociados a las paredes verticales y semiverticales de los principales circos glaciares, con desarrollos que pueden llegar a ser de $350-$ $400 \mathrm{~m}$. Los canales son de trazado variable y fuertes pendientes, generalmente subverticales. Dado el escaso desarrollo de las zonas de alimentación y la verticalidad de los mismos suelen dar lugar a procesos de alta frecuencia y baja intensidad. En este caso la fracturación local se convierte en un factor fundamental a la hora de explicar la distribución y características de los canales de aludes, y es frecuente que sobre la cresta de un mismo circo se formen varios canales de aludes que alimentan las depresiones glaciokársticas situadas a sus pies.

b) Canales de aludes de gran desarrollo: Elaborados sobre escarpes rocosos verticales o subverticales, se asocian comúnmente a los frentes de las escamas de cabalgamiento (de varios cientos de metros de desnivel) y a las incisiones de los desfiladeros y gargantas. Tienden a ser muy verticales y de trazado variable, en función de las condiciones morfotectónicas y topográficas locales. Este tipo de formas suele dar lugar a procesos de alta intensidad y una frecuencia entre baja y media para los casos de mayor magnitud y alta para los de reducidas dimensiones (Fig. 5). Modelan las canales que vierten hacia las grandes gargantas de los tres macizos: Cares, Duje, Urdón, Los Beyos o La Hermida. El encajamiento y desnivel de las mismas, con desarrollos verticales que pueden llegar a ser de 1.500-2.000 m, favorece el desencadenamiento de aludes de nieve frecuentes e intensos, fenómeno de sobra conocido por montañeses y montañeros. Pero existen otros muchos ejemplos de canales de gran desarrollo, como los localizados bajo las crestas del reborde meridional de los tres macizos. En este caso, los desniveles existentes se deben a condicionantes estructurales, al coincidir con los frentes de las escamas de cabalgamiento, siendo frecuente encontrar allí canales de aludes con un notable desarrollo vertical, en ocasiones de más de 600-700 m. En Ándara, las canales de fuerte pendiente, modeladas en cabecera por los glaciares y con las áreas de acumulación a sotavento, sobre las que se desarrollan amplias cornisas, favorecen el desarrollo de grandes aludes en Cortés, Lechugales y Las Arredondas, donde aludes de fondo que alcanzan con frecuencia los 800 m (González Trueba y Serrano, 2009), en sucesos extraordinarios llegan hasta los $600 \mathrm{~m}$, como ha sucedido en el año 2009.

c) Canales de aludes asociados a las topografías características de los dorsos de las escamas cabalgantes: Poseen amplias zonas de alimentación y pendientes mode- 


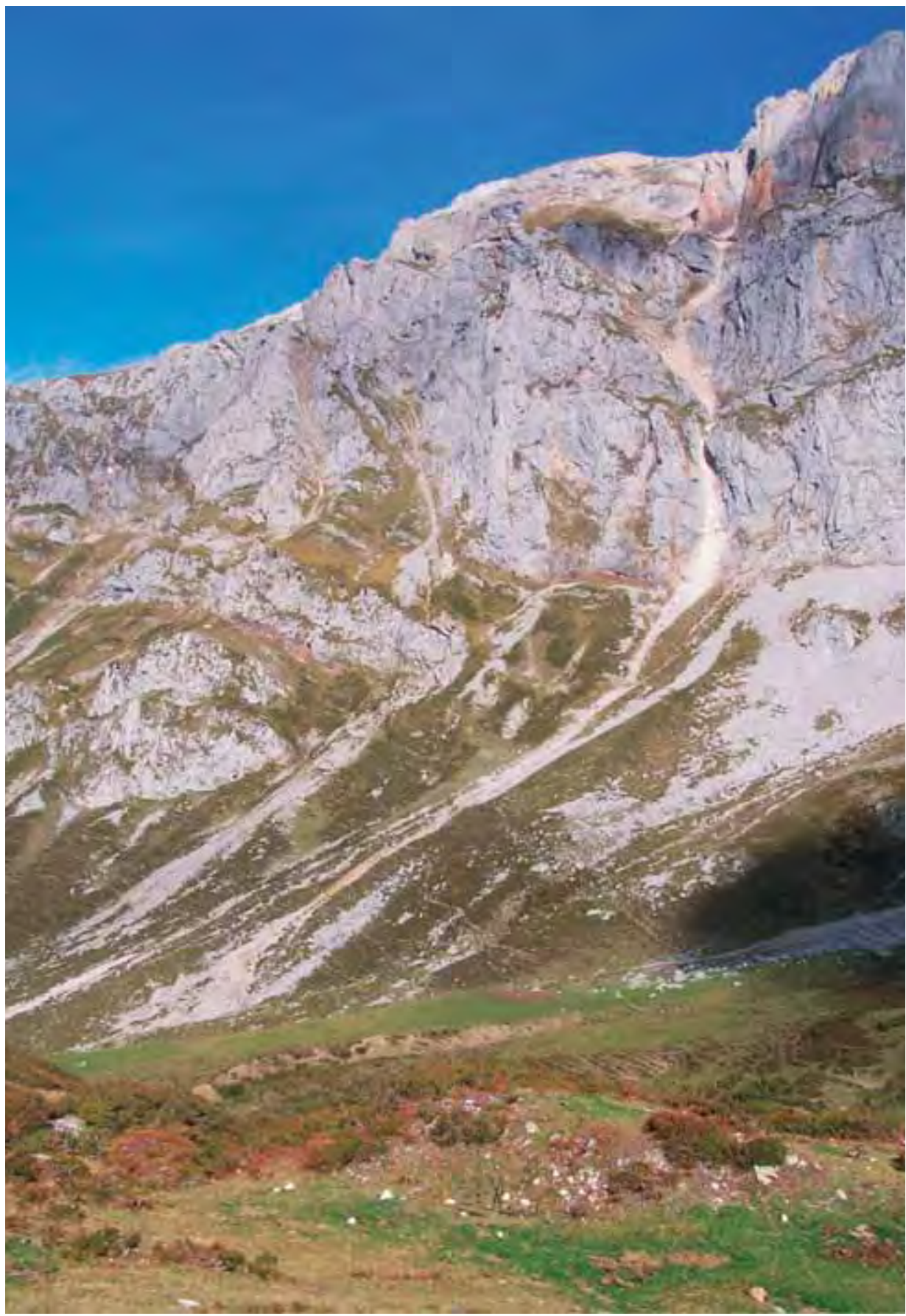

Figura 5. Canal de aludes a favor del escarpe del frente de cabalgamiento meridional, Altos del Verde (Macizo Occidental). 
radas que favorecen la acumulación de gran cantidad de nieve, así como un canal de evacuación con un perfil transversal abierto y longitudinal caracterizado por pendientes medias menores que el caso anterior. Además suelen presentar un trazado mucho más rectilíneo, lo que compensa su menor inclinación y favorece el aumento de la velocidad de caída de la nieve y con ello de su capacidad morfológica. Por sus características topoclimáticas y altitudinales, suelen dar lugar a aludes de alta intensidad y una frecuencia entre baja y media para los más excepcionales y alta para los de menor tamaño. El condicionante morfoestructural que dirige estas formas implica que se orienten preferentemente al norte, a barlovento de los frentes dominantes, con importantes sobreacumulaciones de nieve que posibilitan los importantes aludes de las laderas de La Varera y Acebuco en los Urrieles (Fig. 6).

d) Canales de aludes mixto-complejos: Representados por las formas de evacuación compleja existentes en las numerosas canales que drenan hacia las gargantas fluviales. En ellos se combinan e interactúan las canales de aludes de pequeño desarrollo en la parte de cabecera, y las canales principales de gran desarrollo vertical, fuerte pendiente y trazado variable. Por su complejidad topográfica, los desniveles y pendientes existentes y el rango altitudinal que abarcan, desde la zona de

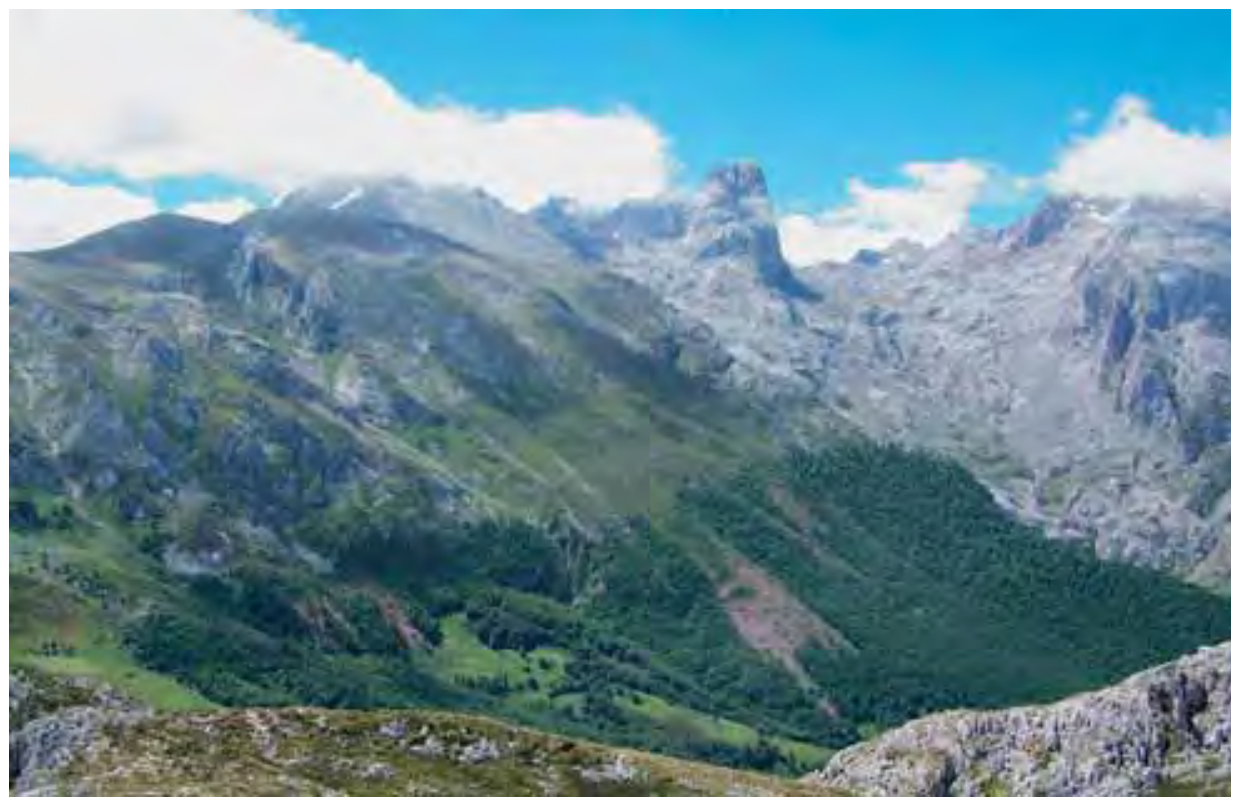

Figura 6. Canal de aludes a favor de las amplias cuestas del dorso de escama estructural, Cuesta las Moñas (Macizo Central). Son bien visibles los efectos de los aludes en el hayedo de la Varera. La fisonomía y grado de recubrimiento de la formación muestra los terrenos afectados por aludes según su magnitud y en distintos períodos de retorno. 
cumbres hasta el fondo de los valles, pueden dar lugar a una gran variedad de aludes tanto en lo que respecta a su frecuencia, como a su intensidad y capacidad morfológica. Los aludes de pequeño tamaño son muy frecuentes, pero en estos sectores se pueden localizar aludes de gran magnitud y con una frecuencia comparativamente mayor a la de otros sectores. En las pedreras y conos mixtos al pie de estas canales, la sobrealimentación nival genera estratos de nieve diferenciales en el manto nival favorables a la puesta en marcha de grandes aludes de placa, como el ocurrido en La Vueltona (Macizo Central) en la primavera de 2009.

En definitiva, la capacidad modeladora de los aludes de nieve viene determinada por las características, frecuencia e intensidad de los mismos, lo cual está directamente relacionado con dos tipos de factores fundamentales:

- Factores climáticos: Por un lado con la variabilidad meteorológica interanual, dependiendo de la cantidad y distribución en el tiempo de las nevadas. Por otro, las condiciones y tipo de nieve, húmeda muy a menudo, generan la inestabilidad del manto nival y una elevada capacidad morfológica de los aludes desencadenados. Otro factor es el período de recurrencia de los aludes de mayor magnitud, que funcionan como procesos con gran capacidad modeladora.

- Factores topográficos: La topografía de detalle de las paredes, el desarrollo longitudinal y vertical del canal, el rango altitudinal, las pendientes, la orientación, el trazado más o menos rectilíneo, o la morfometría de las distintas partes del canal (zona de acumulación/arranque, zona de evacuación y zona de deposición) son factores fundamentales que explican la frecuencia e intensidad de los aludes y su capacidad modeladora en los Picos de Europa.

Si los canales constituyen la forma erosiva más representativa de los aludes, los materiales transportados por la nieve en su caída son depositados al pie de los canales dando lugar a la génesis de unas formas de acumulación propias: los conos. Desde un punto de vista morfológico, los conos de aludes se caracterizan por un tamaño comparativamente menor a otros derrubios de ladera de génesis diferente. Presentan perfiles longitudinales convexos y fuertes pendientes. Debido a la modalidad del aporte de material, en superficie se caracterizan por una mala clasificación, con profusión de finos, organización caótica en superficie con clastos aristados y heterométricos, así como bloques de gran tamaño en las zonas periféricas. Además, los canales de aludes, que funcionan como conductores de nieve y roca durante el invierno, cuando desaparece el manto nival se convierten en eficaces canalizadores del agua y derrubios, de tal modo que en los conos depositados en su base, se producen procesos complementarios, procesos gravitatorios, reptación, flujos de derrubios, torrencialidad, que retocan las formas nivales (Serrano y González Trueba, 2004, González Trueba, 2007a).

\subsection{La acumulación de nieve: los neveros y su acción morfológica}

Los neveros son acumulaciones de nieve en lugares favorables que retardan su fusión hasta entrado el verano e incluso pueden perdurar durante uno o más veranos. Su 
presencia genera procesos geomorfológicos asociados a su movimiento, al deslizamiento de bloques en superficie, a su influencia térmica y al lento aporte de las aguas durante su fusión, capaces de generar formas de detalle en las laderas en las que se inscriben. Aunque tienen menor relevancia paisajística que las originadas por los aludes, las formas derivadas de la nivación son muy frecuentes en las laderas de los sectores más altos. Los neveros son un elemento característico de los Picos de Europa, si bien casi todos los veranos el macizo queda completamente desprovisto del manto nival. Los neveros que más perduran e incluso permanecen a finales del verano se localizan al abrigo de las caras norte de las cumbres y crestas más altas $(>2.400-2.500 \mathrm{~m})$, o alojados en las dolinas y simas de la alta montaña, generalmente, a cotas por encima de los $2.000 \mathrm{~m}$ (Fig. 7).

Durante el verano, estas manchas de nieve poseen una dinámica diaria muy contrastada, con fusión durante el día, principalmente en el cuerpo de nieve, drenando hacia el interior, y generando en la base una rápida pérdida de masa con las características escamas de fusión; mientras que por la noche, se rehiela y deja de fundir, cesando la alimentación de agua a su entorno. Además, durante la noche se genera un equilibrio térmico con el sustrato, si bien durante el día, cuando la roca se calienta, el nevero ejerce de fuente de frío que afecta a su entorno inmediato. Dicha actividad implica la fusión lenta de toda la masa, no sólo de la superficie, donde el elevado albedo disminuye la fusión superficial. En su base, el nevero pierde lentamente volumen y superficie, mientras la acción de las aguas de fusión, la presión de la nieve sobre el suelo y las variaciones térmicas entre el sustrato, el nevero y las formaciones superficiales, alteran su entorno y crean formas características. La actividad nival se centra en el sustrato y en las formaciones superficiales, con formas de disolución nival, el karst nival, característicos de la alta montaña de los Picos, que completa el conjunto de formas nivales.

- Nichos de nivación: Estas formas de erosión nival constituyen pequeñas depresiones donde se alojan los neveros. La alteración térmica de sus bordes y la saturación por agua genera la alteración y evacuación de los materiales, con la consiguiente pequeña y lenta profundización en torno a la acumulación de nieve que cada año incide más. Este proceso, más eficaz sobre depósitos sedimentarios que sobre el sustrato, crea pequeñas depresiones semicirculares en las que no existe colonización vegetal. Sobre el sustrato calizo, este proceso interacciona con la disolución, formando nichos de nivación en las dolinas de disolución características de los sectores más altos.

- Formas nivokársticas: El karst actual de los Picos de Europa se define como un holokarst nival templado-oceánico, caracterizado por una importante zona de recarga difusa sobre sustratos abiertos y con condiciones nivales capaces de desarrollar lapiaces y dolinas de reducidas dimensiones, a favor de la acumulación y persistencia nival. El karst nival se caracteriza por las elevadas tasas de ablación y la baja incidencia periglaciar, sólo capaz de afectar a los lapiaces en las zonas altas. En la actualidad es plenamente activo y define, junto al modelado glaciar, el paisaje de la más alta montaña. Las formas más características son los lapiaces y las dolinas nivokársticos: 


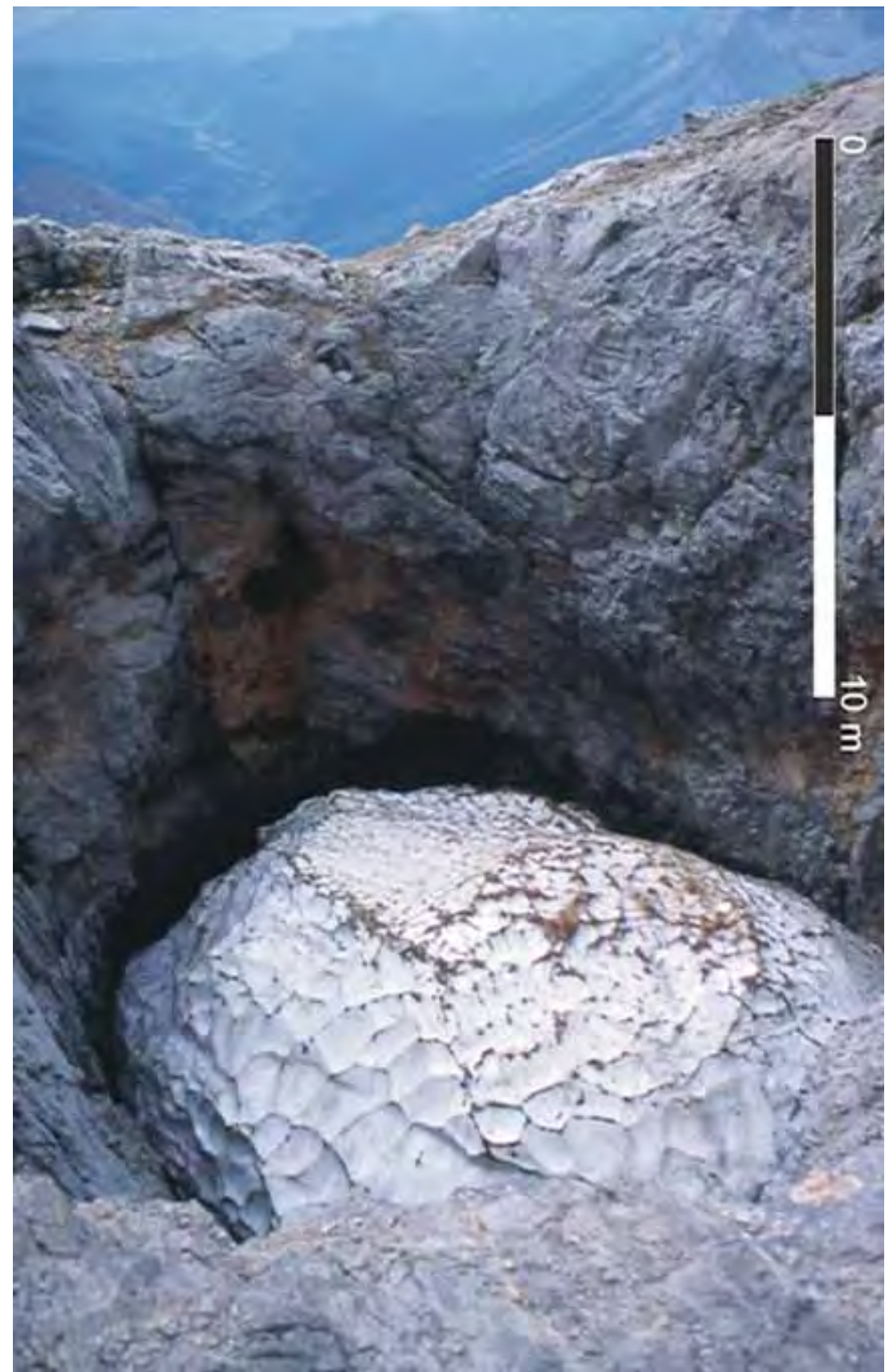

Figura 7. Nevero permanente alojado en el fondo de un pozo kárstico a $2.220 \mathrm{~m}$ en el circo sur del Llambrión (Macizo Central). La depresión ofrece una eficaz protección ante la radiación solar. La permanencia del lentejón de nieve, y los procesos derivados del mismo trabajan el fondo y los laterales del pozo. 
a) Lapiaces libres de alta montaña nivokársticos: Miotke (1968) atribuyó estas formas a la escorrentía laminar o canalizada procedente de la fusión lenta de la cobertura nival. Son lapiaces independientes de las características mineralógicas o estructurales, donde los procesos dominantes son la disolución por las aguas de fusión nival y, en menor medida la gelifracción. Los más característicos son los lapiaces en regueros agudos (rillenkarren), desarrollados en pendientes subverticales a verticales $\left(60-80^{\circ}\right)$, generados por los aportes diarios de la fusión nival, y los lapiaces en surcos (rinnenkarren), desarrollados sobre superficies de inclinación más moderada donde las aguas de fusión nival se canalizan en pequeños canales. La relación entre los canales y surcos meandriformes (maanderkarren) y los procesos nivales es estrecha, como demuestran su abundancia en la cercanía de los neveros (Miotke, 1968).

b) Dolinas de disolución nival: forman cortejos de depresiones menores ubicadas en la alta montaña, en el interior de los circos y depresiones glaciokársticas mayores. Constituyen una forma muy característica de los tres macizos de Picos de Europa, que han sido denominadas como "microdolinas" (Colignon, 1985) por su reducido tamaño, 20-30 metros de anchura, y sus morfologías redondeadas y en embudo. La nieve acumulada en las depresiones perdura hasta bien avanzado el verano, realizando durante meses una aportación lenta y constante de aguas muy frías, y por tanto agresivas, que profundizan y ensanchan la depresión. La acción química se desarrolla en superficie o bajo la cobertura nival, directamente sobre el sustrato o bajo muy delgados y porosos tapices de derrubios. Las aguas circulan rápidamente, pero el flujo constante por la fusión, con ritmos diurno-nocturnos, y la agresividad de las aguas permiten una eficaz actividad morfogenética. Este es el proceso principal en la elaboración de las dolinas nivales, pero se complementa con procesos nivales mecánicos en las porciones más altas de la dolina, donde el nevero ejerce una labor de erosión mecánica, preferentemente si existen formaciones superficiales o tectonización en el sustrato. Este proceso favorece el ensanchamiento hacia la parte alta de la ladera, donde perdura más tiempo el nevero, tendiendo a la disimetría de las dolinas, pues la acumulación de la nieve y la inclinación de la ladera determinan un mayor desarrollo de la depresión pendiente arriba.

- Morrenas de nevero: Son acumulaciones de derrubios en forma de arco que bordean los neveros. Se generan por la caída de clastos y su acumulación al frente del nevero por deslizamiento o caída tras su fusión. Estas formas se caracterizan por la ausencia de finos, la posición planar de los bloques orientados hacia la máxima pendiente y el escaso relieve del arco, con un perfil tendido al interior y con más pendiente, también moderada, al exterior. Resultan formas poco marcadas, localizadas al pie de paredes fuertemente diaclasadas aprovechando rellanos a media pendiente. Son formas frecuentes al pie de los principales grupos altimontanos, allí donde se conservan durante más tiempo los mayores neveros. 


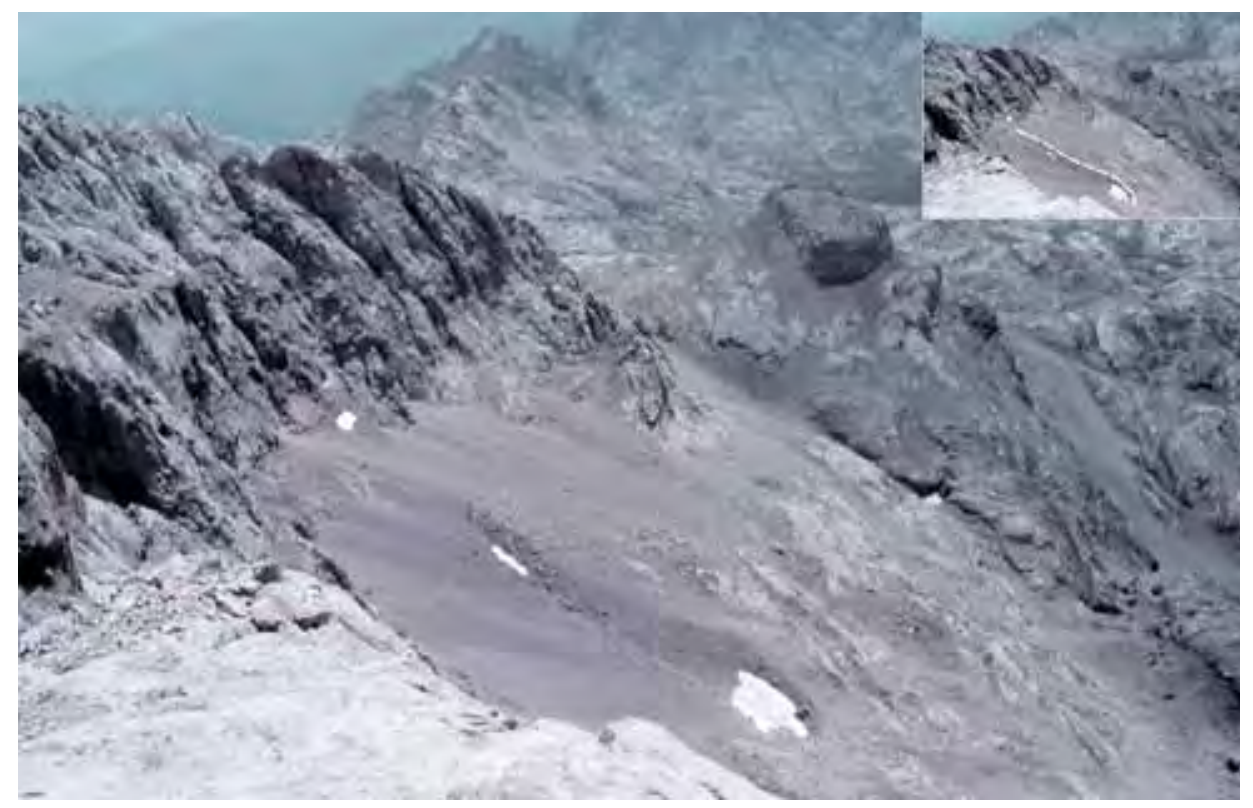

Figura 8. Morrena de nevero activa situada a $2.200 \mathrm{~m}$ en la cara sur de la cresta Torre del Llambrión (2.642 m) - Torre de la Palanca (2.617 m) - Tiro Llago (2.567 m). La morrena se localiza al pie de un talud de derrubios activos, aprovechando un rellano a media ladera.

El grado de actividad de las morrenas de nevero es difícil de establecer, ya que depende de las características, distribución y duración de la cubierta nival, la cual presenta una importante variabilidad interanual. Por ello, se pueden encontrar formas que responden a procesos más o menos continuados durante todo el año, asociados a los neveros permanentes, incluso durante el verano, y otras, por el contrario, cuya actividad se reduce básicamente a la primavera, en relación con manchas de nieve de duración estacional, y que para principios de verano acaban por desaparecer. Además, es posible encontrar morrenas de nevero heredadas, fundamentalmente desde finales del Tardiglaciar-Holoceno, pero aún hoy funcionales o semifuncionales, a distintas alturas y orientaciones, generalmente en torno a los 1.800-1.900 m. Existen nichos plenamente funcionales en la actualidad, repartidos por los tres macizos de los picos de Europa, aunque su formación más efectiva está ligada a la perduración de la nieve varios veranos sucesivos durante períodos recientes más fríos $(\mathrm{PEH})$, que generaron las formas y posibilitaron su continuidad. Hoy día su actividad se localiza en umbrías por encima de 2.100-2.300 m, donde las condiciones topoclimáticas posibilitan la perduración de los neveros (Fig. 8). Las morrenas de nevero plenamente activas, en la medida que su localización está directamente determinada por la distribución de los neveros actuales, la disimetría en la conservación de la nieve según la orienta- 
ción, provoca diferencias también en su localización. Así, mientras que en las orientaciones norte se encuentran morrenas de nevero activas en torno a $2.100 \mathrm{~m}$, en las orientaciones sur ascienden hasta los 2.200-2.300 m.

- Enlosados nivales: Bajo los neveros y en su porción frontal, la influencia térmica sobre el suelo, con congelamientos y descongelamientos, así como su saturación por la fusión nival y el peso de la masa de nieve, posibilitan complejos procesos de organización de los clastos, con los finos en profundidad, parcialmente lavados, y los gruesos en superficie, estos últimos en posición planar, que configuran un enlosado de bloques sobre una formación de finos saturada. Frecuentemente están alteradas como consecuencia de los hundimientos de material asociado al karst cubierto, que irregulariza las superficies y altera las formas. Sus reducidas dimensiones están en relación con la extensión de los neveros y su carácter estacional. Se localizan en los fondos de las depresiones glaciokársticas y en los umbrales con formaciones superficiales por encima de los $2.000 \mathrm{~m}$.

\section{Conclusiones}

Las condiciones climáticas derivadas de su localización en fachada oceánica, especialmente su régimen térmico y pluviométrico, hace de los Picos de Europa un macizo de alta montaña atlántica (hiperhúmedo) caracterizado por las frecuentes e intensas precipitaciones en forma de nieve. Este hecho favorece la existencia de procesos nivales generalizados en las porciones altas del macizo, que en ocasiones alcanzan también cotas muy bajas, debido a los fuertes desniveles existentes. Sin embargo, son esas mismas condiciones de localización combinadas con la altitud, la topografía, la orientación y la exposición, las que favorecen una cubierta nival inestable y muy variable, siendo éste uno de sus rasgos más definitorios.

La duración de la cubierta nival, 6 meses aproximadamente en torno a $1.500 \mathrm{~m}$ y $8 / 9$ meses por encima de los 2.000 m condiciona la mayoría de los procesos geomorfológicos de la alta montaña, controla el régimen térmico e hídrico del suelo, y es un eficaz agente de modelado. Los datos registrados en Picos de Europa muestran un régimen térmico muy dependiente de la constitución y evolución del manto nival, de forma que las distintas fases en la evolución anual de las temperaturas del suelo varían considerablemente tanto temporal como espacialmente.

Los procesos nivales más eficaces son los aludes, la erosión directa del sustrato por la acción térmica y química de las aguas de fusión, el deslizamiento y movimiento de derrubios sobre la superficie de los neveros y durante su fusión, y la alteración mecánica de la formación superficial infrayacente. Todos ellos generan formas características del modelado de la alta montaña de los Picos de Europa. Aunque en general son formas de detalle, de dimensiones moderadas, su análisis aporta una interesante información sobre la dinámica del medio altimontano en el que se inscriben, además de mostrarnos el importante papel de la nieve como agente de modelado directo e indirecto. 
La alta montaña de los Picos de Europa se caracteriza por una morfodinámica de tipo nivoperiglaciar, con unas condiciones estrictamente periglaciares restringidas a la zona de cumbres. En los dos pisos morfoclimáticos que conforman el cinturón de alta montaña: nivoperiglaciar (1.800-2.200 m) y crionival (>2.200), son fundamentales y dominantes los procesos nivales, nivokársticos y crionivales. Se trata de un medio de alta montaña marginal, en el que, tras su completa deglaciación, el frío y el hielo van perdiendo significación morfológica y paisajística frente a la nieve, sus procesos y formas asociadas; es la respuesta morfogenética de la montaña a los cambios ambientales recientes y actuales.

\section{Agradecimientos}

Este trabajo se desarrolla en el marco de los proyectos de investigación de la CICYT CGL2007-65295/BTE y del Ministerio de Medio Ambiente OAPN 007/2007.

\section{Referencias bibliográficas}

Brosche, K.U. (1978b). Formas actuales y límites inferiores periglaciares en la Península Ibérica. Estudios Geográficos, 151: 131-161.

Brosche, K.U. (1994). Ergebnisse von Abtragungsmessungen an periglazialen Solifluktionsschuttdecken in vier Hochgebirgen der Ibersichen Halbinsel (Picos de Europa, Peña Prieta, Sierra de Urbión und Sierra Nevada). Eiszeittalter u. Gegenwart, 44: 28-55.

Castañón, J. C., Frochoso, M. (1994). El periglaciarismo de la Cordillera Cantábrica. En: Periglaciarismo de la Península Ibérica, Canarias y Baleares (Gómez Ortiz, A., Simón Torres, M., Salvador Franch, F., Eds.). Monografías de la SEG, Universidad de Granada, pp. 75-91, Granada.

Castañón, J. C., Frochoso, M. (1998). La alta montaña cantábrica: condiciones térmicas y morfodinámica en los Picos de Europa. En: Procesos biofísicos actuales en medios fríos (Gómez Ortiz, A. Salvador Franch, F. Schulte, L. García Navarro, A. eds). Universidad de Barcelona, pp. 113-132, Barcelona.

Clarck, R. (1981). Cold climate features of the Cordillera Cantábrica, northern Spain. Biuletin Peryglaciar, 28: 5-13.

Collignon, B. (1985). Les Picos de Europa. Quelques élements de geológie et d'hydrologie. Spelunca, 19: 7-12.

Chardon, M. (1984). Montagne et haute montagne alpine, critéres et limites morphológiques remarquables en haute montagne. Revue de Geographie Alpine, 82 (2-3-4): 213-224.

Francou, B. (1988). L'Eboulisation en Haute Montagne. Thèse d'Etat, Editec. Grenoble. 
GonzÁlez Martín, J. A. (1984). Rasgos generales del periglaciarismo de la Península Ibérica y áreas insulares. I. Dominio atlántico. Lurralde, 23-81.

GonzÁlez Trueba, J. J. (2007a). El paisaje natural del Macizo Central de los Picos de Europa: Geomorfología y sus implicaciones geoecológicas. CIMA, Consejería de Medio Ambiente, Gobierno de Cantabria, 598 pág., Santander.

GonzÁlez Trueba, J. J. (2007b). Geomorfología del Macizo Central de los Picos de Europa. Con mapa geomorfológico del macizo central de los Picos de Europa E 1:25.000. OAPN, Ministerio de Medio Ambiente, 231 pp., Madrid.

González Trueba, J. J. (2007c). La Pequeña Edad del Hielo en los Picos de Europa. Servicio de Publicaciones de la Universidad de Cantabria / Fundación Marcelino Botín, 320 pp., Santander.

González Trueba, J. J., Serrano, E. (2009). Geomorfología del Macizo Oriental (Ándara) de los Picos de Europa. Con mapa geomorfológico del macizo oriental de los Picos de Europa E 1:25.000. OAPN, Ministerio de Medio Ambiente, 245 pp., Madrid. (En prensa).

González Trueba, J. J., Serrano, E., González García, M. (2009). Mapa geomorfológico del Macizo Occidental (Cornión) de los Picos de Europa E 1:25.000. OAPN, Ministerio de Medio Ambiente, Madrid. (En prensa).

HAEBERLI, W. (1985). Creep of mountain permafrost: internal structure and flow of alpine rock glaciers. Mitteilungen der Versuchsanstalt für Wasserbau, Hydrology und Glaziology, 77 pp., Zurich.

HARris, S. A. (1988). The alpine periglacial zone. En: Advances in Perglacial geomorphology (Clark, M. J., Ed.). Wiley and Son Public., Nueva York.

Hoelzle, M., Wegmann, M., Krummenacher, B. (1999). Miniature temperature dataloggers for mapping and monitoring of permafrost in high mountain areas: first experience from the Swiss Alps. Permafrost and Periglacial Processes, 10: 113-124.

IsHIKAWA, M. (2003). Thermal regimes at the snowground interface and their implications for the permafrost investigation. Geomorphology, 52: 105-120.

IVES, J. D. (Ed.) (1980). Geoecology of the Colorado Front Range: A study of Alpine and Subalpine Environments. Westview Press, Boulder, Colorado.

Ives, J. D. (1986). Mountain environments. Progress in Physical Geography, 10 (3): 437-445.

KARTE, J. (1983). Periglacial phenomena and their significace as climatic and edaphic indicators. GeoJournal, 74: 329-340.

KING, L. (1986). Zonation and ecology of high mountain permafrost in Scandinavia. Geografisca Annaler, 68 (A-3): 131-139.

Kotarba, A., Kaszowski, L., Krzemien, K. (1987). High mountain denudational system of the Polish Tatra Mountains. Polish Academy of Science, Cracovia. 
Marquínez, J. (1988). Mapa geológico de la Región del Cuera y Picos de Europa (Cordillera Cantábrica, NW España). Trabajos de Geología, 18: 137-144.

Marquínez, J., Adrados, L. (2000). La geología y el relieve de los Picos de Europa. Naturalia Cantabricae, 1: 3-19.

MiотKe, F. D. (1968). Karstmorphologische studien in der glacial-überformten Höhenstufe der Picos de Europa, Nordspanien. Selbtverlagder Geografhischen Gessesllschaft, 4.

Muñoz Jiménez, J. (1982). Geografía Física. El relieve, el clima, las aguas. En: Geografía de Asturias (F. Quirós, Ed.). Ayalga, Oviedo.

Serrano, E., GonzÁlez Trueba, J. J. (2004). Morfodinámica periglaciar en el Grupo Peña Vieja (Macizo Central de los Picos de Europa-Cantabria-). Rev. C. \& G., 18 (3-4): 73-88.

WashbuRn, A. L. (1979). Geocryology. A survey of periglacial processes and environments. Arnold, London. 